\title{
Tecnologia REAC: abordagem bioelétrica do processo saúde doença.
}

Ana Rita Pinheiro Barcessat (1)

\section{EDITORIAL}

A forma como se enxerga o processo saúde doença há muito vem sendo discutida , a partir de um modelo focado no adoecer e na cura das enfermidades deixa-se de lado as dimensões mais abrangentes e mergulha-se nos meandros dos caminhos, por vezes complexos, da patogênese das coisas.

Os fluxos iôicos endógenos são considerados reguladores chave do comportamento celular, antes de uma condição ou uma doença ser visível e /ou detectável do ponto de vista molecular ou bioquímico, ocorreram prévias alterações bioelétricas ${ }^{1}$ que impactaram a polaridade das células do órgão ou tecido em questão, ou seja, impactaram na forma da célula gerir seus fluxos e circuitos internos, como a distribuição morfológica de suas organelas, do cito esqueleto, da organização proteica, incluindo aí as histonas, proteínas intimamente ligadas ao DNA celular, gerando assim alterações denominadas epigenéticas. ${ }^{2}$

Epigenética é um termo utilizado para designar o estudo de alterações estáveis no potencial de expressão dos genes, durante o desenvolvimento e a proliferação das células, assim seus mecanismos parecem permitir que um organismo responda ao ambiente por meio de mudanças na expressão gênica. ${ }^{2}$ Os processos epigenéticos identificam a modificação póssintética do próprio DNA ou de macromoléculas que se associam intimamente a ele como mediadores-chave. Essas alterações parecem ser interpretadas por proteínas que reconhecem uma modificação particular e facilitam os efeitos biológicos subsequentes. ${ }^{2,3}$.

O meio externo, representado pelo ambiente e sua interação com o sistema nervoso, pode alterar os campos bioelétricos endógenos celulares e por conseguinte a polaridade celular, uma vez mantida essa alteração ativam-se mecanismos epigenéticos, cujos estudos estão altamente focados, dentre outros processos, na metilação do DNA e na modificação das histonas, essas alterações apesar de hereditárias a curto prazo, não implicam em modificações na fita do DNA portanto não são genéticas, a grande questão reside em que 
medida as influências ambientais podem gerar alterações epigenéticas ${ }^{2,4}$. Tome-se como exemplo o estresse.

Qualquer situação de estresse põe em risco a vida, a menos que seja enfrentada por respostas adaptativas adequadas, inversamente, qualquer coisa que coloque a vida em risco causa estresse e respostas adaptativas, sustenta Hans Selye no clássico manuscrito intitulado Síndrome geral da adaptação de $1951^{5}$. Quando se está em sistema de alarme, a partir da ativação do sistema nervoso autônomo, ou seja, organicamente pronto para lutar ou fugir, bloqueiam-se circuitos neuronais mais refinados como o de procurar por uma célula mutada por câncer ou infectada por um vírus, o organismo não estará ocupado em reproduzir, regular hormônios ou ser imunologicamente competente, pois a situação que se encontra é de emergência, arregimentando assim todas as energias para os circuitos que lhe permitirão lutar ou fugir, o que naquela situação é entendido como normal , no entanto, quando esse quadro de alarme perdura, e isso acontecerá por meio circuitos neurovegetativos inconscientes, a constante ativação dos circuitos de luta ou fuga, em função daquilo que o sistema nervoso comanda como um novo padrão de normalidade, estabelecerá a desativação dos demais circuitos, alterará os campos bioelétricos ao redor das células e a polaridade celular com consequentes alterações epigenéticas, percorrendo o caminho do estresse à doença ${ }^{2-5}$.

O adoecimento tendo como base o estresse é bem conhecido, em especial para mecanismos imunossupressores. Na etapa conhecida como exaustão na resposta estresse, os hormônios não se esgotam e a resposta acaba se tornando mais prejudicial do que o estressor, o corpo gasta energia no estresse e na defesa às custas do crescimento, da reprodução, e de outras funções vitais, surgindo então as doenças e condições debilitantes como respostas adaptativas disfuncionais ${ }^{4}$. A modulação do estresse e a otimização das respostas bioelétricas orgânicas podem ser a chave para a redução do adoecimento.

A tecnologia REAC, acrônimo do termo em inglês Radioeletric assimetric conveyer Conversor radioelétrico assimétrico, foi desenvolvida para ajudar a restabelecer a polaridade celular por meio do reequilíbrio dos campos bioelétricos endógenos, modulando e otimizando as respostas adaptativas, pois a reprogramação e otimização dos campos permitem modular processos epigenéticos e por conseguinte a expressão gênica, em contraste com processos inflamatórios, senescentes e neurodegenerativos ${ }^{6,7}$.

Tratam-se de pulsos radioelétricos de baixa frequência cuja interação com o organismo otimiza a resposta corporal. Dividida em protocolos de bio e neuromodulação a tecnologia REAC apresenta evidências importantes no manejo de doenças neurodegenerativas e transtornos psicofísicos, reparo de lesões e medicina regenerativa ${ }^{6-10}$

Vanguarda de tecnologias em saúde o REAC consiste em uma estratégia terapêutica para a reaquisição de qualidade de vida, por meio de um cérebro consciente e capaz de restaurar seu correto funcionamento, garantindo a recuperação ou manutenção do estado de saúde ${ }^{6}$, a tecnologia é um campo promissor aberto a pesquisas de aplicação nas mais diversas áreas. 
Palavras Cheave: Tecnologia REAC, Bioeletrcidade, Lazer.

Instituição afiliada: 1- Cirurgiã Dentista - Estomatologista. Doutora em Patologia Oral e Maxilo Facial pela Universidade de São Paulo - USP; Professora de Citologia, Histologia, Patologia e Imunologia da Universidade Federal do Amapá- UNIFAP; Líder do Grupo de Pesquisa em Biofotônica e modulação Radiolelétrica em saúde e do Núcleo de Estudos em Neuro Psico Fisiopatologia Adaptativa - UNIFAP — Brasil; Doutoranda em Genética Médica - Universidade De Sassari - Itália *

Dados da publicação: Artigo recebido em 10 de Dezembro, revisado em 10 de Dezembro, aceito para publicação em 20 de Dezembro e publicado em 29 de Dezembro.

DOI: https://doi.org/10.36557/2674-8169.2020v2n13p01-04 Ana Rita Pinhairo Barcessat ritabarcessat@gmail.com

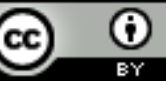

This work is licensed under a Creative Commons Attribution 4.0 International

License. 


\section{REFERÊNCIAS}

1.MCLAUGHLIN, Kelly A.; LEVIN, Michael. Bioelectric signaling in regeneration: mechanisms of ionic controls of growth and form. Developmental biology, v. 433, n. 2, p. 177-189, 2018.

2. JAENISCH, Rudolf; BIRD, Adrian. Epigenetic regulation of gene expression: how the genome integrates intrinsic and environmental signals. Nature genetics, v. 33, n. 3, p. 245-254, 2003.

3. LISTER, Ryan et al. Global epigenomic reconfiguration during mammalian brain development. Science, v. 341, n. 6146, 2013.

4. LOTTERHOS, Katie E. et al. Modularity of genes involved in local adaptation to climate despite physical linkage. Genome Biology, v. 19, n. 1, p. 157, 2018.

5. SELYE, Hans. Stress and the general adaptation syndrome. British medical journal, v. 1, n. 4667, p. 1383, 1950.

6. Zippo AG, Rinaldi S, Pellegata G, Caramenti GC, Valente M, Fontani V, Biella GE. Electrophysiological effects of non-invasive Radio Electric Asymmetric Conveyor (REAC) on thalamocortical neural activities and perturbed experimental conditions. Sci Rep. 2015

7. Maioli M, Rinaldi S, Santaniello S, Castagna A, Pigliaru G, Delitala A, Lotti Margotti M, Bagella L, Fontani V, Ventura C. Anti-senescence efficacy of radio-electric asymmetric conveyer technology. Age (Dordr). 2014 Feb;36(1):9-20.

8. Rinaldi A, Rinaldi C, Coelho Pereira JA, Lotti Margotti M, Bittencourt MN, Barcessat ARP, Fontani $\mathrm{V}$, Rinaldi S. Radio electric asymmetric conveyer neuromodulation in depression, anxiety, and stress. Neuropsychiatr Dis Treat. 2019

9. Coelho Pereira JA, Rinaldi A, Fontani V, Rinaldi S. REAC neuromodulation treatments in subjects with severe socioeconomic and cultural hardship in the Brazilian state of Pará: a family observational pilot study. Neuropsychiatr Dis Treat. 2018 Apr 16;14:1047-1054.

10. A, Mendoza C, Zea MA, Frades B, Rinaldi S, Martínez-Martín P. Motor effects of radio electric asymmetric conveyer in Alzheimer's disease: results from a cross-over trial. J Alzheimers Dis. 2014;42(1):325-32. 